\title{
DEL TÁLAMO AL TÚMULO: CLARA JERÓNIMA, VICENTE TORELLAS Y ROQUE GUINART (Don Quijote, II ${ }^{\mathrm{a}}$ Parte, Caps. 60, 61)
}

Haciéndole ir a D. Quijote por tierras catalanas, Cervantes, ya por su característica preocupación con la autenticidad histórica, debió de considerar oportuno ingeniar un encuentro entre aquél y el bandolero Roque Guinart, protector 0 amenaza — según el punto de vistade la gente de esa región por aquella época. ${ }^{1}$ En efecto, en algunos estudios se destaca esta preocupación de Cervantes como justificativa del notorio episodio, aunque sustentada por un deseo simultáneo de contrastar al dinámico, activo, pragmático "caballero" Roque Guinart con D. Quijote, quimérico "caballero andante", anacrónico, inútil frente a los problemas que surgen durante su encuentro. ${ }^{2}$ Descartada como ridícula, absurda, la oferta de D. Quijote de socorrer a Claudia Jerónima, "doncella agraviada" 3 , la impotencia, es decir, la superflua existencia de aquél se haría por completo patente, anunciando asi el inminente fin de sus empresas caballerescas. ${ }^{4}$ Esta sugerencia resulta plausible, pero no abarca la implicación más significativa de la "inutilidad" de D. Quijote en ésta y algunas otras situaciones semejantes.

La introducción de Clara Jerónima se considera a veces superflua: "está de más" en la novela, ${ }^{5}$ o, cuando más, como mero pretexto para relatarse otro cuento, el cual, además, es un desacierto: "A girl disguised as a young man in green arrives at a gallop with the usual story: Man promised to marry her, now he is about to marry another. She shoots him, but it transpires that the rumors were wrong and she falls fainting on his body as he breathes his last. Idiotic!"6 "Idiótica" concepción novelística, sin reconocible relevancia para la novela. En éste, como en todos los estudios que conocemos, queda desapercibida la importancia de

1 Ver las notas a los capítulos 60-61, Ira Parte del Quijote, ed. de M. de Riquer, Barcelona, Juventud, 1965.

2 S. Lorente-Murphy y R. M. Frank, "Roque Guinard y la justicia distributiva", «A. C.», 1982, p. 109;

A. Weber, "Don Quixote with Roque Guinart: The Case for an Ironic Reading", Cervantes, 1986, p. 135;

R. L. Hathaway, "Claudia Jerónima", «N.R.F.H.», 1988, p. 320;

L. A. Murillo, A Critical Introduction to Don Quixote, New York, Lang, 1988, pp. 236-237.

3 En este episodio trágico Sancho proporciona un instante de alivio cómico, con un zeugma: "mi señor tiene muy buena mano para casamentero...; y si no fuera porque los encantadores lo persiguen... esta fuera la hora en que ya la tal doncella no lo fuera" (1480), reminiscente del de Dorotea, con implicación muy seria: "al salir mi doncella del cuarto, yo dejé de serlo" (1152). Para todas las citas de las obras cervantinas utilizamos la edición de la Obras completas de Cervantes, de A. Valbuena Prat, Madrid, Aguilar, 1965.

4 R. L. Hathaway, "Claudia Jerónima”, p. 320 y sig.; L. A. Murillo, A Critical Introduction to Don Quixote, 236-7.

5 Clemencín, citado por V. Gaos, en su edición de El ingenioso hidalgo Don Quijote de la Mancha, Madrid, Gredos, 1987, $I I^{a}$ Parte, p. 852.

6 V. Nabokov, Lectures on Don Quixote, London, 1983, p. 203; citado por Hathaway. 
las tan incisivas referencias a la alianza política del padre de la joven con Roque Guinart en los sangrientos conflictos de los bandos catalanes. Esta trágica circunstancia política se contempla como detalle histórico, ambiental, novelísticamente conveniente y bien utilizado, pero, al fin de cuentas, fácilmente sustituible por otro cualquiera que funcionase como obstáculo formidable para la libre comunicación entre los dos enamo-rados.

La perplejidad todavía patente de muchos lectores frente a este famoso episodio se debe, esencialmente, al hecho de que no se ha percibido la íntima relación poética, novelística, "histórica" entre la actuación de Don Quijote y las de Roque Guinart y Claudia Jerónima. ${ }^{7}$ Creemos que sólo comprendiendo bien esta relación es posible apreciar la gran sutileza de la concepción novelística, la transcendencia de la visión política, social y, sobre todo, moral de Cervantes en este episodio y, en definitiva, su relevancia en el Quijote. Cabe mostrar, pues, la función de cada elemento particular en el conjunto, en su mutua dependencia con los otros elementos con que, únicamente, todos cobran su pleno sentido.

Dejando aparte a sus enemigos del bando de los Cadells, "los lladres que su perdición procuran" (1483), todos los que encuentran a Roque Guinart quedan "admirados" de su extraordinaria personalidad. " $\mathrm{OOh}$ gran Roque!", “ $\mathrm{O}$ h valeroso Roque!”, “ $\mathrm{A}$ Alejandro Magno!", etc. (1479, 1480, 1483), lo aclaman con sincero fervor, al evocar su ya mítica fama de valentía, gallardía, nobleza de espíritu, magnanimidad, discreción, pericia y astucia militar..., $\mathrm{y}$, al ver comprobadas todas estas virtudes legendarias en su conducta, en particular, en su "extraño proceder" (1483), que es su honrado, compasivo, humanitario trato con todos; sin excluir a los enemigos, ${ }^{8}$ y especialmente con los desvalidos en cualquier adversidad: "Infinitas y bien dichas fueron las razones con que los capitanes agradecieron a Roque Guinart su cortesía y libertad...; la señora doña Guiomar de Quiñones se quiso arrojar del coche para besar los pies y las manos del gran Roque..." (1483). Por su caballerosidad hacia las mujeres y por su consideración de la siempre precaria condición económica del soldado $\rightarrow$ y quizás también de la supuesta honradez de la profesión soldadesca-, Roque Guinart les ha quitado a estos viandantes sólo una partecilla del dinero que traían, lo mínimo "para contentar esta escuadra que me acompaña" (1483), sus revoltosos "escuderos". A los peregrinos, por pobres - con lo que se nos sugiere que eran religiosos genuinos - hasta les da diez escudos del botín. Incluso "pide perdón del agravio que... hacia, forzado de cumplir con las obligaciones precisas de su mal oficio" (1483). Significativamente, del botín que reparte entre sus "escuderos" Roque Guinart no guarda nada para sí y en una ocasión dice que no es

7 Esto se revela a menudo en la tendencia de tratar alguno de sus elementos separada o preferentemente, como si fuese más bien independiente de los otros, según lo sugieren ya los títulos de los estudios: Azorín: "El misterio de Claudia", Con permiso de los cervantistas, Madrid, 1948, pp. 115-116; Unamuno sólo habla de Roque Guinart y ni menciona a Claudia Jerónima ( $L a$ vida de D. Quijote y Sancho, Obras completas, Madrid, A. Aguado, 1958, vol. IV, pp. 319-329); K. L. Selig, "Some Observations on Roque Guinart", en Medieval, Renaissance and Folklore Studies in Honor of J. Esten Keller, Newark, J. de la Cuesta, 1980, pp. 237-279; S. Lorente-Murphy y R. M. Frank, "Roque Guinart y la justicia distributiva en el Quijote", pp. 103-111; A. Weber, "D. Quixote with Roque Guinart"; R. L. Hathaway, "Claudia Jerónima", etc.

8 "Roque Guinart ordenó a los criados de don Vicente que llevasen su cuerpo al lugar de su padre, que estaba allí cerca para que le diesen sepultura" (1481). Tan galante actitud frente a los enemigos no era de ningún modo corriente entre los miembros de los bandos. La Galatea: "Ruego a los altos cielos... que permitan que tu cuerpo carezca de sepultura..." (615), aunque en este caso interviene una fuerte razón personal. 
"buen contador" (1483), detalle revelador de su despreocupación por asuntos monetarios, gananciales. Los viandantes que caían en poder de bandoleros consideraban como hecho providencial si éstos eran capitaneados por Roque Guinart, según lo comprueba también el "encuentro" que refiere el estudiante pícaro de La cueva de Salamanca, aludiendo evidentemente a una creencia popular divulgada por toda España: "robáronme los lacayos o compañeros de Roque Guinart en Cataluña, porque él estaba ausente; a estar allí, no consintiera que se me hiciera agravio, porque es muy cortés y comedido, $\mathrm{y}$, además, limosnero" (588). ${ }^{9}$ En suma, Roque Guinart era la única esperanza en tal adversidad para muchos viandantes, en particular, para los pobres, las mujeres y los niños, de todos los cuales aquél solía compadecerse: "no quiso que pasase adelante su tristeza" (1483), y de quienes fue, por ello, muy admirado. La opinión de que el autor ironiza "la cortesía y liberalidad" de Roque Guinart con la observación de "que por tal la tuvieron [los capitanes] en dejarles [aquél] su mismo dinero", 10 se desentiende, entre otras cosas, de la calificación anterior, asimismo del autor, de que las "razones" de gratitud fueron "bien dichas" (1483). Se destaca la situación irónica en que los capitanes se encuentran, y su plena conciencia de que sin la intervención de Roque Guinart se quedarían en cuero y, posiblemente, sin vida. En un mundo en que todas las autoridades, incluso las oficiales, regían a menudo con cínico, total descuido de la legalidad y la justicia, 11 el bandolero Roque Guinart, paradójicamente, parecía una excepción a muchos, cuya admiración por él no se nos sugeriría así como "misplaced". $12 \mathrm{El}$ propósito del autor de destacar la "cortesía" y la "liberalidad" de Roque Guinart se evidencia ya por el hecho de que introduce sólo a viandantes con quienes el bandolero tiene ocasión de demostrarlas. Formidable amenaza para sus enemigos, Roque Guinart es, por otra parte, benévolo, generoso, providencial amparo para los desvalidos e inocentes.

Sin embargo, respecto a la "cortesía y liberalidad" de Roque Guinart con los viandantes (a base de sus relativas posesiones) y a la repartición de lo robado "por toda su compañia, con tanta legalidad y prudencia, que no pasó un punto ni defraudó nada de la justicia distributiva" (1482), es preciso disentir de aquellos lectores que equiparan esto con cierta visión utópica respecto a la redistribución de la riqueza en la sociedad: "Roque está tratando de enmendar entuertos que realmente existen...; altera el significado práctico de justicia del entonces vigente proceso socioeconómico: recauda bienes de entre los que más tienen y los reparte entre los más necesitados"; 13 proclamando a Roque Guinart como un "enlightened ruler of a mini-state". $14 \mathrm{Al}$ distribuir todo entre sus "escuderos", Roque Guinart explica a D. Quijote que "si no se guardase esta puntualidad con éstos, no se podría vivir con ellos" (1482). Practica esta "justicia distributiva", porque es el único modo de convivir con

9 Ver nuestro estudio sobre este entremés en El teatro de Cervantes, Madrid, Castalia, 1992.

10 A. Weber, “Don Quixote with Roque Guinart...", pp. 133-134.

11 H. Kamen: "In general all banditry, both aristocratic and popular, was criminal; but it was a form of crime that rose out of political and social crisis and out of economic disorder. Banditry did not cause crisis; it was itself the result of a crisis" (The Iron Century: Social Change in Europe, 1550-1660, London, 1971, p. 341).

12 A. Weber, "Don Quixote with Roque Guinart...", p. 134.

13 S. Lorente-Murphy, y R. M. Frank, "Roque Guinard y la justicia distributiva", p. 109-110.

14 K. L. Selig, "The Ricote Episode in D. Quixote: Observations on Literary Refractions", «RHM», 1974-5, p. 75. Visión idealizadora de la "justicia distributiva" de Roque Guinart ya en Unamuno, La vida de Don Quijote y 
¡"estos"! —nótese el patente desprecio personal-, cuyos servicios necesita. La traviesa observación de Sancho se refiere de modo preciso a esta precaria naturaleza de la covivencia bandolera: "Según lo que aquí he visto, es tan buena la justicia, que es necesario que se use aun entre los mismos ladrones" (1482). En suma, Roque Guinart practica la "justicia distributiva" porque de ello depende su propia sobrevivencia y no porque aquélla fuese parte de un programa político, en oposición al "status quo". 15 A todas luces, ideas de reforma social y económica no animan en absoluto su bandolerismo, que es de carácter radicalmente personal.

Para poder "vivir con ellos", Roque Guinart debe recurrir también a la más rigurosa disciplina frente a cualquier acto de insubordinación. Oyendo la objeción de un "escudero" a su liberalidad con los viandantes: "Este nuestro capitán más es para frade que para bandolero" -reveladora perspectiva negativa frente a la bondad natural del jefe-, Roque Guinart, "echando mano a la espada, le abrió la cabeza casi en dos partes", diciendo "desta manera castigo yo a los deslenguados y atrevidos... Ninguno le osó decir palabra: tanta era la obediencia que le tenían" (1483). Castigo riguroso, brutal, pero revelársele a esta "buena gente" como "frade" sería de seguro fatal para Roque Guinart. Sus "escuderos" son mercenarios que le sirven sólo por el provecho que derivan de las actividades bandoleras ("el abad, de lo que canta yanta", 1483), bajo su habilísimo mando, sin ningún sentimiento de genuina lealtad o compañerismo, por lo cual también podrían venderse en cualquier momento a cualquiera que les pagase mejor: "Roque pasaba las noches apartado de los suyos, en partes y lugares donde ellos no pudiesen saber dónde estaba...; no se osaba fiar de ninguno, temiendo que los mismos suyos, o le habían de matar o entregar a la justicia" (1484). Gente de bajísima calidad humana en todos los sentidos, lo que se condensa en la irónica calificación del autor: "buena gente" (1479), de quien Roque Guinart debe servirse para sus guerras con los Cadells, pero con quien no comparte ningún otro interés, ningún atributo personal, y a quien debe tratar con disciplina férrea para su propia sobrevivencia. ${ }^{16}$ Se prescinde de todas estas consideraciones cuando se declara que "this incident [el castigo] undercuts Roque's own assertion that he is by nature merciful and well meaning." 17 Es posible, sin embargo, que con ese incidente Cervantes se proponga, simultáneamente, destacar un rasgo distintivo del temperamento catalán, según algunos contemporáneos suyos lo comprendian: "en las injurias muestran gran sentimiento y por eso son inclinados a venganza." 18

Roque Guinart se preocupa de hacer saber a todo el mundo que su bandolerismo no tiene nada en común con el bandidaje de sus "escuderos", de i"estos"!, individuos codiciosos, sólo

Sancho, p. 322 y sigs.; y en A. Castro, El pensamiento de Cervantes, Barcelona-Madrid, Noguer, 1972, pp. 193-94, 210, en que se enjuician las declaraciones y la actuación de Roque Guinart con increíble descuido del contexto.

15 No tienen en cuenta este hecho crucial los estudios mencionados en las notas 13, 14. Por otra parte, se menciona en el de A. Weber, "Don Quixote with Roque Guinart...", p. 130.

16 Extrañamente, no hace esta distinción Unamuno: "Tengo, pues, para mí que Roque Guinart y sus compañeros eran mejores de lo que ellos mismos se creian" (La vida de Don Quijote y Sancho, p. 328).

17 A. Weber, "Don Quixote with Roque Guinart...", p. 134.

18 F. Manuel de Melo, Historia de los movimientos, separación y guerra de Cataluña en tiempo de Felipe $N$, p. 1645. Citado por Unamuno, (La vida de Don Quijote y Sancho, p. 351). 
interesados en la rapiña de "los bienes ajenos." El no se ha hecho bandolero para "robar, matar y saltear", sino por razones de honor personal y del de toda su familia, según él lo entiende. Esto es lo que quiere hacer saber siempre cuando la ocasión se le presenta, como al dar a Sancho los "diez escudos..., porque pueda decir bien desta aventura" (1483). ¿Por qué culparle de mero afán de "theatrical gesture and rhetoric", de "self-dramatizing gallantry"? 19 Claro que le interesa mucho mantener en cuanta más estima su reputación de dignidad, nobleza e integridad personal ipreservadas pese a todas las circunstancias tan desfavorables a ellas? ${ }^{20}$ según ya se ha dicho, pero ninguna indicación hay de que "dramatice" consciente, calculadamente su persona y su vida de bandolero para impresionar a la gente. Todo lo contrario: Roque Guinart "no ensalza su estado", 21 que considera como "el modo de vivir más inquieto" y "sobresaltado", un "laberinto de confusiones", en que se encuentra por unos "deseos de venganza... de un agravio" que se le hizo, y del cual quisiera salir a "puerto seguro", pero "a despecho y pesar de lo que entiendo", confiesa, esos "deseos" dan "con todas mis buenas inclinaciones en tierra" (1482).

Las "buenas y concertadas razones" de Roque Guinart dejan "admirado" a D. Quijote, pues "pensaba que entre los de oficios semejantes, de robar, matar y saltear no podía haber alguno que tuviese buen discurso" (1482). Este se manifiesta en toda la actuación del bandolero. Según la paráfrasis de la carta a Antonio Moreno, que nos ofrece el autor, Roque Guinart demuestra que sabe escribir con soltura, discreción, gracia y cierto sentido de humor (con probable resabio cínico, que se condiserará más adelante). Cita la Biblia en varias ocasiones, y una vez con variación personal, algo juguetona, con que quiere consolar a Don Quijote y a Sancho, a punto de ser "espulgados" por los bandoleros: "el cielo, por extraños y nunca vistos rodeos... suele levantar los caídos y enriquecer los pobres" (1480), y en que, dicho sea de paso, no percibimos esa supuesta obsesión de Roque Guinart con lo "económico", 22 desmentida de raíz por toda su conducta. El "buen discurso" de Roque Guinart, en lo que toca a su educación formal, no se contradice tampoco por el hecho de que diga a Don Quijote: "No estéis tan triste, buen hombre, porque no habéis caído en las manos de algún Osiris" (1479), en vez de decir Busiris, rey legendario, quien sacrificaba a los viandantes a Júpiter. "Error de bulto";23 "malapropismo" revelador de la "ignorancia y presunción" del bandolero, ${ }^{24}$ concluyen algunos lectores, representando una opinión más bien general. Se nos explica que el error no puede ser de Cervantes, supuestamente siempre "exacto" en tales cosas. ${ }^{25}$ Dejando aparte esta afirmación insostenible, la gran semejanza fónica de Osiris Busiris haría perfectamente comprensible el error de Roque Guinart, en que, creemos, podría caer fácilmente aun la persona más erudita y versada en mitos y leyendas que no hubiese tenido ocasión reciente de evocar esos nombres. Visto esto así, el error de Roque Guinart no

\footnotetext{
19 A. Weber, "Don Quixote with Roque Guinart...", pp. 133-134.

20 K. L. Selig, "Some Observations on Roque Guinart”, pp. 276-277.

21 Unamuno, La vida de Don Quijote y Sancho, p. 235.

22 A. Weber, "Don Quixote with Roque Guinart...", p. 129.

23 V. Gaos, El ingenioso hidalgo Don Quijote de la Mancha, p. 844.

24 A. Weber, “Don Quixote with Roque Guinart...", p. 129.

25 Opinión de Clemencín, citada por V. Gaos, El ingenioso hidalgo Don Quijote de la Mancha, p. 844.
} 
sugeriria ninguna grave falta en su cultura. No revelándose, pues, este error como malapropismo significativo para la caracterización del personaje ni como "juego de rebote... del humor cervantino" 26 ni tampoco como símbolo convincente de una eventual regeneración ${ }^{27}$ ¿qué otra posible función tendría en el episodio? Con toda probabilidad, se trata de una confusión de Cervantes mismo, o quizá del tipógrafo, tan comprensible en cualquier caso: “... quisiera yo que los tales censuradores fueran más misericordiosos y menos escrupulosos... aliquando bonus dormitat Homerus" (Quijote, 1284). ${ }^{28}$ Hemos insistido en estos detalles para destacar el hecho improtante de que Roque Guinart no se nos retrata como persona ignorante o presuntuosamente culta, como piensan algunos lectores, pues, de ser tal su condición, se podría quizás atribuir a ella, entre otras causas, su bandolerismo. Sin embargo, sus "buenas y concertadas razones" son "admirables", sobre todo, por indicar la clara conciencia que Roque Guinart tiene de sus propios defectos, que quisiera enmendar, por revelar su esencial bondad y nobleza personal, pese a su extraviada vida bandolera. Roque Guinart es "mejor de lo que él mismo se cree",29 concluye inevitablemente el lector que lo observa y escucha con atención. Y es por intuir esta buena naturaleza en Roque Guinart que Don Quijote le aconseja, como medio posible de salvación, la caballería andante. El consejo impráctico, de que se ríe Roque Guinart, como también el lector, no desvirtúa la muy certera intuición. ${ }^{30}$

En este fatal "laberinto de confusiones" que son las continuas guerras fratricidas entre los Cadells y los Nierros, bando a que él pertenece, Roque Guinart es instrumento activo de la violencia, pero también, en gran parte, víctima casi inerme del torbellino feroz que destruye a todo su pueblo. Es para dramatizar esta catástrofe nacional de un modo cuanto más representativo, compresivo, que Cervantes introduce a Clara Jerónima; al lado del activo bandolero, un miembro no combatiente de su "familia" - ambos convertidos en instrumentos de la violencia y ambos, simultáneamente, su víctima — constituyéndose simbólicamente en la gran "familia" agonizando en un atroz tormento infernal. 31 "... Sintieron a sus espaldas un ruido como de tropel de caballos, y no era sino uno solo, sobre el cual venía a toda furia un mancebo... con daga y espada dorada, una escopeta pequeña en las manos y dos pistolas a

26 J. B. Avalle-Arce, Los trabajos de Persiles y Segismunda, Madrid, 1969, p. 345. No se explica en qué precisamente consistiria el "humor" en este caso. Sería impropio comparar este "malapropismo" con tantos otros, auténticamente cómicos, en las obras cervantinas.

$27 \mathrm{~K}$. L. Selig: “.... it may be an authorial manipulation to presage a/the resolution of the total episode with a ray of hope and reconciliation, since Osiris... is associated with fertility, renewal, resurrection and hope" "Some Observations on Roque Guinart", p. 275). No resulta relevante la aplicación de este sentido a Roque Guinart, quien, de hecho, niega la relación con Osiris.

$28 \mathrm{Y}$ es, por fin, posible que no haya error en absoluto. Según algunos editores, "también se sacrificaban extranjeros a Osiris, a quien probablemente se remonta la leyenda de Busiris" (Ver V. Gaos, El ingenioso hidalgo Don Quijote de la Mancha, p. 845).

29 Unamuno, La vida de Don Quijote y Sancho, p. 328.

30 A. Weber: “...the mad Knight appends to it an absurd coda which quickly diffuses the seriousness of sensitive controversy" (Don Quixote with Roque Guinart...", p. 132).

31 Roque Guinart fue eventualmente indultado por las autoridades y murió como soldado del ejército español en Italia. Así, las consecuencias de la guerra de los bandos no fueron, en definitiva, trágicas para él, como lo fueron para mucha gente buena, a menudo por completo inocente, hasta desinteresada en esas feroces rivalidades y muy 
los lados...: En tu busca venia, joh valeroso Roque!, para hallar en ti, si no remedio, a lo menos alivio en mi desdicha ..., soy Claudia Jerónima..."(1480). La "furia" descabellada con que aparece, las muchas armas con que viene cargada, la extrema alteración emocional, apuntan ominosamente al violento, draconiano acto que acaba de cometer: "alcancé a don Vicente obra de una legua de aquí, y sin ponerme a dar quejas ni a oír disculpas, le disparé esta escopeta y, por añadidura estas dos pistolas...; le debí de encerrar más de dos balas en el cuerpo, abriéndole puertas por donde envuelta en su sangre saliese mi honra" (1480). Don Vicente, "olvidado de lo que [le] debía, se casaba con otra... esta mañana", nueva que a ella le "turbó el sentido y acabó la paciencia", con las consecuencias que se ha visto (1480). Don Vicente es hijo de Clauquel Torrellas, quien es enemigo de Simón Forte y éste es padre de Claudia Jerónima y aliado de Roque Guinart en las guerras de los bandos catalanes. Por esta razón Claudia Jerónima viene a pedirle a Roque Guinart que la "pase a Francia", donde ella tiene "parientes", y que defienda a su padre, "porque los muchos de don Vicente no se atrevan a tomar en él desaforada venganza" (1480). Las venganzas se están "eslabonando", como advierte Roque Guinart (1482), requiriendo siempre más víctimas.

Cervantes trató el amor de dos jóvenes de familias enemigas ya en La Galatea: "[eran] los parientes de entrambos de los más principales del lugar y estaba en ellos el mando y gobernación del pueblo", pero "la envidia, enemiga mortal de la sosegada vida, sobre algunas diferencias del gobierno del pueblo vino a poner entre ellos cizaña y mortalísima discordia; de manera que el pueblo fue dividido en dos parcialidades: la una seguía la de mis parientes [de Lisandro], la otra la de los de Leonida, con tan arraigado rencor y mal camino, que no ha sido parte para ponerlos en paz ninguna humana diligencia" (617). Parece anunciarse una trágica historia amorosa, por la causa específica de una feroz guerra de bandos, aunque en un casi mítico mundo pastoril: "una aldea... en las riberas del Betis... en la gran Vandalia", etc. (616), y la anticipación de tal desarrollo episódico se refuerza por las esporádicas referencias a "la endurecida enemistad de los padres", como obstáculo para que los amantes puedan "descubrirse los pensamientos" (617); a la paz entre las familias que Lisandro desearía lograr casándose con Leonida, por lo cual también se demuestra tan tolerante del desmandado Crisalvo, hermano de aquélla (619); a la esperanza de la bien intencionada Silvia de "poder dar principio al fin de [esa] discordia" con un casamiento de los hijos (617), argumento, entre otros, con que también intenta influir en Leonida (618); a la convicción de Crisalvo de que Lisandro rivaliza con él por el amor de Silvia, por causa de la antigua enemistad de sus familias (619); a la declaración de Crisalvo de que dio muerte a Silvia por estar ésta enamorada de Lisandro, "enemigo" de la familia (621), etc. 32 Sin embargo, dicha anticipación del lector queda por completo frustrada. La "enemistad de los padres" sirve como mero pretexto para complicar cuanto más la trama, un más bien convencional cuadrángulo amoroso pastoril: Lisandro ama a Leonida, quien le corresponde, mientras Crisalvo, hermano de Leonida, ama a Silvia, quien no le corresponde. Por esta razón, "toma la amistad" de Carino, "pariente" de Silvia, para que influya en ella. Carino promete tal intercesión, pero

deseosa de paz y armonía. Es por esta razón que en Roque Guinart se dramatiza, sobre todo, su conflicto íntimo durante su bandolerismo.

32 Todas estas referencias (y varias otras que no citamos) a la enemistad de las familias de los amantes tienen paralelo, a veces literal, en las dos obras que proponemos como fuentes en las notas 34 y 35 . 
secretamente odia a Crisalvo como también a Lisandro, por unas humillaciones sufridas en el pasado. Convence a Crisalvo que Silvia no lo quiere a él porque está enamorada de Lisandro y que éste está a punto de llevársela a una aldea para casarse con ella. Con unos cómplices, Crisalvo mata a Leonida y Libeo, en el camino, pensando, según las señas que le dio Carino, que los dos son Silvia y Lisandro. Este castiga a Crisalvo y a Carino matándolos y después sigue viviendo con el deseo de morir cuanto antes para "tornar a ver" a su querida Leonida. La razón principal de la tragedia es, pues, el "rencor", "la mala voluntad", el "odio perpetuo" de Carino, por unas juveniles rivalidades amorosas y las "condiciones dobladas" con que lleva a cabo su perversa, monstruosa venganza personal. La enemistad de las familias es sólo parte del fondo, incidental, sin transcendencia alguna más allá de su conveniencia para la trama y, en realidad, fácilmente sustituible, como obstáculo episódico para los amantes, pues es de valor neutral en el sentido ideológico, filosófico y moral (612-622).

A la misma conclusión se llega al considerar las fuentes literarias - extrañamente todavía no señaladas -, 33 de que Cervantes probablemente se sirvió, aunque modificándolas mucho, para este cuento. Tanto en la Istoria di due nobili amanti de Luigi da Porto ${ }^{34}$ como en la Novella LX, de la Seconda Parte, de Bandello, ${ }^{35}$ se sitúan los amores de los dos jóvenes en un ambiente de intensos odios entre sus familias, los notorios Montecchi y Cappelletti; que se resuelven en una conciliación, por lo menos momentánea, frente a la trágica muerte de sus queridos hijos: "In questo tempo i padri loro nella detta chiesa vennero, e sopra i loro morti figliuoli pignendo, da doppia pieta vinti (avvegnache inimici fossero), s'abbracciarono, in modo che la lunga nimistà tra essi e tra le loro case stata, e che nè prieghi di amici, nè minaccia del signore, ne danni recevuti, nè tempo avea potuto estinguere, per la misera morte di questi amanti ebbe fine"; 36 "Il que [la muerte de los hijos] fue cagione che tra i Montecchi e Cappelletti si fece la pace, ben che non molto dapoi durasse". 37 Sin embargo, falta, notablemente, cualquier implicación condenatoria del odio de las familias, como causa directa de la tragedia, así como se aprecia en Romeo and Juliet de Shakespeare: "See what a scourge is laid upon your hate, / That heaven finds means to kill your joys with love". 38

${ }^{33}$ Es una excepción esta pasajera referencia de M. Moner, al hablar de los amores de Clara Jerónima y Vicente: "On reconnaît ici les premices de la trame héritée de Bandello et immortalisée par Shakespeare, que Cervantès a déjà exploitée dans la Galatea à travers l'histoire de Lisandro et Leonida" (Cervantès conteur: écrits et paroles, Madrid, Casa de Velazquez, 1989, p. 149).

34 Istoria novellamente ritrovata di due nobili amanti con la pietosa loro morte intervenuta già nella città di Verona nel tempo del sig. Bartolomeo della Scala [publ. entre 1511-1529]. Utilizamos la edición de A. Torri, Giulietta e Romeo, novella storica di Luigi da Porto, Pisa, 1831.

35 Tutte le opere di Matteo Bandello, ed. de F. Flora, Mondadori, 1952.

36 Istoria di due nobili amanti, p. 46. “... Vino a poner entre ellos [los parientes de los dos amantes] cizaña y mortalísima discordia; ... con tan arraigado rencor y mal ánimo, que no ha sido parte para ponerlos en paz ninguna humana diligencia" (La Galatea, 617). "Inimici", "inimicizia"... En el cuento de La Galatea que tratamos Cervantes utiliza "inimicicia", júnica vez en sus obras! Nos parece evidente que no se trata de un arcaismo, como sugiere J. B. Avalle-Arce en su edición de La Galatea (Madrid, CC., 1968, p. 40), sino de una influencia directa de la fuente italiana, constituyéndose así en otra valiosa prueba de la inspiración literaria para el cuento cervantino de La Galatea y del Quijote.

37 Bandello, Novela $L X, \mathrm{II}^{\mathrm{a}}$ Parte, p. 765.

38 Romeo and Juliet, V, última escena. Sobre el intricado problema de las fuentes de esta obra ver K. Muir, Shakespeare's Sources, London, 1957. 
La "cagione" de la tragedia para Luigi da Porto es el gran amor de los jóvenes y, en particular, de Giulietta, cuyas virtudes exalta como implícito reproche a las mujeres contemporáneas que carecen de ellas. Las desilusiones amorosas del autor se transparentan: "O fedel pietà, che nelle donne anticamente regnavi, ove ora se'ita? In qual petto oggi t'alberghi? Qual donna sarebbe al presente, come la fedel Giulietta fece, sopra il suo amante morta?... Quante ne sariano ora, che non prima l'amante morto veduto arebbero, che trovarne un altro si ariano pensato...? Miseri gli amanti di questa età...", etc. ${ }^{39}$ En su carta dedicatoria, Bandello explica que escribió su novella (probablemente inspirada en la de Luigi da Porto), porque "il suo infelice fine quasi tutti ci fece piangere", al oirla narrada, "e perchè mi parve degna di compassione e d'esser consecrata a la posterità, per ammonir i giovini che imparino moderatamente a governarsi e non correr a furia". 40 En suma, la "discordia" de los padres es en ambos casos, esencialmente, una de tantas circunstancias accidentales que no se contempla como causa del trágico fin de los hijos, desde un punto de vista moral.

Respecto al trágico desenlace en el episodio del Quijote, el autor observa: "Pero, ¿qué mucho, si tejieron la trama de su lamentable historia [de los amores de Claudia Jerónima] las fuerzas invencibles y rigurosas de los celos?" (1481), por lo que se podría pensar que aquí se perpetúa la misma actitud indiferente hacia la discordia de las familias que caracteriza las versiones literarias anteriores. Sin embargo, una lectura atenta del conjunto revela un cambio radical de enfoque. Los "celos" de Claudia Jerónima son tan sólo la última causa, el instrumento inmediato del trágico suceso, manejado con malévolo cálculo para fines perversos. Esta sugerencia empieza a comprobarse en la descripción, de extrema, excepcional concisión y brevedad, de estos amores: "Vicente... viome, requebróme, escuchéle, enamoréme a hurto de mi padre... Finalmente, él me prometió de ser mi esposo, y yo le di la palabra de ser suya, sin que en obras pasásemos adelante. Supe ayer que, olvidado de lo que me debía, se casaba con otra, y que esta mañana iba a desposarse, nueva que me turbó el sentido y acabó la paciencia...; alcancé a don Vicente... le disparé esta escopeta..." (1480). Por cierto, las presiones del momento hacen comprensible que Clara Jerónima quiera "decir en breves palabras" su "desventura" y "abreviar" cuanto más su "cuento" (1480), pero el autor, que tiene toda la comodidad para hacerlo, no obstante prescinde de ofrecer información adicional, más pormenorizada sobre el desarrollo de estas relaciones amorosas. Es que tal información no es necesaria ni, en realidad, relevante, pues lo que a Cervantes interesa revelar, sobre todo, son los malévolos designios y las alevosas maquinaciones maquiavélicas que causan el cruel fin de esos amores, tan bellos y nobles por haber aspirado a sobreponerse al insondable abismo del odio de sus familias. 41

Azorín especula sobre el origen de la falsa nueva del casamiento de don Vicente con Leonora, hija del rico Balvastro: "una buena amiga le diría que su novio no le era fiel; otra

\footnotetext{
39 Istoria di due nobili amanti, p. 46.

40 Novela LX, II ${ }^{a}$ Parte, p. 717. La "moraleja" explícita de esta novella hace evocar la de la Celestina: "reprehesión de los locos enamorados", quedando el lector perplejo, por la misma razón, en ambos casos.

41 Este estilo narrativo corresponde al de "veni, vidi, vici", propuesto por H. Hatzfeld (El Quijote como obra de arte del lenguaje, Madrid, 1949, pp. 311-319), pero con una justificación particular, que se sugiere con nuestra lectura.
} 
le añadiría que sabía de ciencia cierta que su novio iba a casarse con otra; un señor respetable, para evitar tergiversaciones, le confesaría, en secreto, que lo sabía todo: su novio no era su novio; su novio era el novio de otra novia y gradualmente, como suceden estas cosas, Claudia se iría amontonando. Y de pronto salía al encuentro de su novio..." Sin embargo, al ilustre escritor le deja perplejo un detalle extraño y muy significativo: " $¿ Y$ no tuvo Claudia tiempo de enterarse? ¿Y no pudo esforzarse en una investigación de la verdad...? La cosa valía la pena...", y concluye que "Cervantes no nos da luz, ninguna luz, para dilucidar este enigma", este "misterio de Claudia". 42 Ahora bien, cuando Cervantes introduce un "misterio", lo sugiere claramente como tal, inexplicable, por una u otra razón, $\mathrm{o}$, por otra parte, explica, a la postre, sus causas precisas. En nuestro caso, no se nos revela ninguna justificación novelística para crear un "enigma" o un "misterio" inexplicable. El chisme por la envidia, por la mala voluntad, etc., o hasta por el chisme mismo, "el gran galeote", podría constituir una causa plausible, claro está, a la que se inclina la tan "impresionista" especulación de Azorín. Sin embargo, Cervantes no sugiere una propagación "gradual", de boca en boca, de la falsa nueva, como sería característico del chisme, sino su revelación repentina, instantánea, abrupta: "Supe ayer... que esta mañana iba a desposarse" don Vicente (1480). "Nueva" perversamente calculada en su falsedad como también respecto a todas las circunstancias ambientales y temporales en que se la comunicaría a Clara Jerónima: el mismo día en que el padre de la joven no estuviese "en el lugar", para que no le estorbase la salida, ${ }^{43}$ y en que don Vicente se encontrase, por cualquier razón, de camino, en dirección aproximada del "lugar" de Leonora, su supuesta novia. De averiguar el viaje de don Vicente $\longrightarrow$ quizás hasta de ocasionarlo- se encargarían los notorios "espías", de quienes solían servirse los bandos, en toda Europa, como instrumento imprescindible de prevención o emboscada: "Ordinarono castoro [unos vengadores de la honra de familia, en una situación semejante a la cervantina] ciò che bisogno era per dare efetto a tanto omicidio, e cominciarono a spiare tutti gli andamenti del cavaliere [del ofensor, a quien matarian desde una emboscada]". $44 \mathrm{La}$ falsa "nueva" se le daría a Clara Jerónima cuanto más tarde antes del supuesto casamiento de don Vicente, precisamente para que no pudiese "esforzarse en una investigación de la verdad". Es así que Clara Jerónima "alcanza" a don Vicente en el lugar y momento precisos en que, evidentemente, le dijeron que lo encontraria: "apresurado el paso a este caballo, alcancé

42 Azorín, "El misterio de Claudia", p. 116.

43 Algunos lectores se extrañan de que no se encargue de la venganza del pundonor el padre ( $R$. L. Hathaway, "Claudia Jerónima", p. 362). Lo que menos desea este padre es que su hija se case con un miembro del odiado bando contrario. Asi, lejos de insistir en tal casamiento, probablemente celebraria la ruptura de la promesa, particularmente en vista de que no se ha perdido el "honor" de Clara Jerónima: "Sin que en obras pasásemos adelante" (1480). Clara Jerónima no tiene hermanos, probablemente por sugerencia de las fuentes (Luigi da Porto, Bandello), en que Giulietta tampoco los tiene; en éstos casos, como también en Shakespeare, la muerte de un pariente es necesaria para justificar la separación de los dos amantes, ya casados. De allí la muerte del "primo" Tibaldo a mano de Romeo. Todos estos autores sabian que la muerte de un "hermano" crearia problemas íntimos quizás insuperables entre los amantes mismos. Estrella: "Yo te absuelvo la palabra; / que ver siempre al homicida / de mi hermano en mesa y cama / me ha de dar pena". Sancho: "Y a mí / estar siempre con la hermana / del que maté injustamente /; ... por amarla / no es justicia que lo sea [esposo]" (La estrella de Sevilla, última escena).

44 Bandello, Novella LX, Parte Prima, p. 10. La Galatea: "De alli adelante Crisalvo traía espías por ver lo que yo con Silvia pasaba" (619). 
a don Vicente obra de una legua de aqui" (1480)..$^{45}$ Más sorprendente es la perplejidad de Azorín por el "traje de hombre" que Clara Jerónima viste para ir al alcance de su novio: "¿Cómo ha podido hacerse de ayer a hoy... el suntuoso arreo? No serían tardos ni perezosos los sastres de Barcelona. O pensamos que Clara Jerónima tenía la costumbre de pasearese de día o de noche, disfrazada de varón. No tiene hermanos... ¿Estamos en presencia de un virago? ... la Varona de Cataluña..." 46 Para este "misterio" hay varias explicaciones posibles, sencillas: Clara Jerónima debe salir de su "lugar" sin revelar su identidad personal, femenina. Deseando reunirse con Romeo, Giulietta pide a Fra Lorenzo: "Io vorrei, padre mío, che voi mi facessi ritrovar calze, giuppone ed il resto de le vestimenta da ragazzo, a ciò che vestita ch'io me sia, possa la sera sul tardi o il matino a buonissim'ora uscirmene di Verona, che persona non mi conoscerà". ${ }^{47}$ De igual modo, a Clara Jerónima le habrían podido "ritrovar" un traje de hombre, pronto, sin dificultad alguna. El lujo del traje y de las armas, "damasco verde, con pasamanos de oro, gregüescos y saltaembarca, con sombrero terciado, a la valona, botas enceradas y justas, espuelas, daga y espada doradas, una escopeta pequeña en las manos y dos pistolas a los lados..." (1480), hasta sugiere que a Clara Jerónima se los facilitaría alguno de esos parientes o "amigos" cortesanos (que también le dieron la falsa nueva) de su propio vestuario. Teniendo en cuenta esta posibilidad, el traje de hombre de Clara Jerónima no sería de ningun modo "un fait courant dans la litérature espagnole du siècle d'or... [sin] une importance particulière". 48

Los celos por la supuesta traición de don Vicente bastarían para "turbar el sentido y acabar la paciencia" (1480) de Clara Jerónima, pero a la venganza la empuja probablemente también el "honor de familia", pues los perpetradores de la falsa "nueva" de seguro no dejarían de sugerirle que don Vicente se propone humillarla sólo por ser ella de los del "contrario bando" (1480). Es una aprensión que atormenta también a Giulietta, al declarársele Romeo "fedel servo" para siempre: "Oh sciocca me a qual vaghezza mi lascio io in cosi strano labirinto guidare? ...per la nimistà che ha co' miei, altro che la mia vergogna non può cercare"; 49 "... sciocca che sono, che Romeo m'ami? Forse lo scaltrito giovine quelle parole per ingannarmi $m$ 'ha dette..., parendoli forse a questo modo far la vendetta de la nemistà che tutto il di incrudelisce piu tra i suoi e i miei parenti". $50 \mathrm{Y}$, significativamente, la misma clase de sospechas tiene Crisalvo, el hermano de Leonida: "pensaba que por serle yo [Lisandro] ene-

45 Clara Jerónima es de seguro también de temperamento impulsivo, pero su crimen se hace posible por muchas circunstancias, de que ella es también víctima inocente, y que no se tienen debidamente en cuenta en los estudios que la condenan como "atropellada y violenta" (Azorin, "Cervantes y el amor", Con permiso de los cervantistas, p. 57); "energúmena" (F. Márquez Villanueva, Temas y personajes de Quijote, Madrid, Taurus, 1975, p. 34); patológicamente "suspicaz" (K. Togelby, La estructura del Quijote, Sevilla, 1977, p. 80); etc. Las situaciones de Clara Jerónima y Dorotea son por completo distintas, por lo cual resulta impropio concluir que a aquélla "le falta el control" de ésta (R. L. Hathaway, "Claudia Jerónima", p. 326).

46 Azorín, "El misterio de Claudia", p. 116.

${ }^{47}$ Bandello, Novella LX, II Parte, p. 747.

${ }^{48}$ L. Combet, Cervantès ou les incertitudes du désir, Lyon, 198?, p. 288. Hector P. Márquez: "el disfraz se explica de una manera lógica" (La representación de los personajes femeninos en el Quijote, Madrid, Porrúa T., 1990, p. 151).

49 Luigi da Porto, Istoria di due nobili amanti, p. 23.

50 Bandello, Novella LX, Ira Parte, p. 734. 
migo, había procurado tratar amores con Silvia, y no porque yo bien la quisiese. Y esto le acrecentaba la cólera y enojo de manera que le sacaba de juicio" (619). Cabe imaginar la existencia de parientes y "amigos" de Clara Jerónima de la naturaleza maliciosa de Crisalvo o del "mal talento e fellone ánimo" de los "parenti e amici" de esa "fanciulla degli Amidei", quienes matan cruelmente, en una emboscada, a messer Buondelmonte, por disponerse éste al casamiento con una "rara beltà", olvidado de la promesa de matrimonio hecha a aquélla (nótense los paralelos con nuestro episodio), pues "quella ingiuria e si manifesta onta non era a modo veruno da sopportare..., cosi vituperosa macchia non si poteva, se non con l'istesso sangue del nemico e dispregiator dell'affinità loro, lavare". 51 Con esta brutal venganza, en nombre del honor de familia, comienza la notoria, interminable guerra de los bandos florentinos. Estos "parenti e amici" condenarian, pues, cualquier relación entre las mujeres de su bando y los hombres del bando contrario, por presuponerla como un truco de éstos para humillar todo el bando, pero, probablemente, sobre todo, por considerarla como un acercamiento indeseado a sus odiados enemigos; atizadores fanáticos del odio y de la violencia entre los bandos, a quienes, de modo significativo, Dante representa en el notorio Mosca de Lamberti, en su Inferno: "Ei son tra l'anime più nere...; mal seme per la gente tosca". 52

La historia y la literatura que tratan de estas multiseculares guerras de los bandos proporcionan abundante información sobre las atrocidades de que éstos eran capaces. Con su breve episodio, tan denso en sutiles implicaciones, Cervantes representa una de las más horripilantes atrocidades concebibles, al mostrar cómo la perversa maquinación política despoja a Clara Jerónima de su discreción y conciencia, convirtiéndola en instrumento ciego, deshumanizado del implacable odio sectario induciéndola hasta a destruir por su propia mano al ser que más quiere en el mundo: "y sin ponerme a dar quejas ni a oír disculpas, le disparé... Allí le dejo entre sus criados..." (1480). Ni a Shakespeare en su Romeo and Juliet se le ocurrió un desenlace trágico tan henchido de penosa ironía, resaltado por la revelación de la verdad: " $\mathrm{i} O \mathrm{O}$ cruel e inconsiderada mujer..., con que facilidad te moviste a poner en ejecución tan mal pensamiento!" (1481), ${ }^{53}$ y la realización de Clara Jerónima de que don Vicente la quería siempre con amor entrañable, hasta tal punto que "tiene [su] suerte por venturosa" por el mero hecho de poder "dejar [su] vida" en las "manos" y en los "brazos" de ella, y que, lejos de reprocharle su precipitado acto, se le ofrece "por esposo", como la "mayor satisfacción" que él, en estos trances, puede darle i“del agravio que [ella] piensa que de [él] ha

51 Ibid., Novella $L X, I^{a}$ Parte, p. 8-9, 10.

52 Dante, Inferno, Canto VI, verso 85; Canto XXVII, verso 108. Fue Mosca quien incitó a matar a Buondelmonte.

53 En este caso, Clara Jerónima se reprocha justamente por el terrible error que acaba de cometer, pero, en otra ocasión, su rencor contra toda la naturaleza femenina ("no hay mujer, por retirada que esté y recatada que sea, a quien no le sobre tiempo para poner en ejecución y efecto sus atropellados deseos", 1480) se debe, evidentemente, a la falsa información que tiene de la integridad de don Vicente. En las relaciones con éste, ningún "atropellado deseo" tuvo ella, si no es que se considere como tal su atrevimiento de amar a don Vicente, pese al odio de sus familias. Esta perspectiva temporal, emocional, equivocada de Clara Jerónima inválida la opinión de que “en el Quijote, la última palabra la tiene la corriente misógina tradicional por boca, sí, de una mujer, Claudia Jerónima", quien "todavia no ha resuelto, siendo mujer, la contradicción entre la imperfección (estupidez) congénita del sexo débil y su astucia diabólica" (J. Joset, "Amor de mujer noble: una grieta en el baluarte aristocrático de la sociedad estamental", Actas del I Coloquio Internacional de la Asociación de Cervantistas, Barcelona, Anthropos, 1990, p. 154). 
recibido"! (1481). Don Vicente pide perdón a la amada por el error que ella ha cometido, ejemplificando de la manera más excepcional esta "reflexión" de la Rochefoucauld: "On pardonne tant que l'on aime". 54

Habiéndose enterado de que ya "su dulce esposo no vivía, [Clara Jerónima] rompió los aires con suspiros, hirió los cielos con quejas, maltrató sus cabellos, entregándolos al viento, afeó su rostro con sus propias manos, con todas las muestras de dolor y sentimiento que de un lastimado pecho pudieran imaginarse", haciendo llorar a todos: "Todo aquel circuito parecía campo de tristeza y lugar de desgracia" (1481). 55 Después de "muchos desmayos" declara "que querría irse a un monasterio..., en el cual pensaba acabar la vida, de otro mejor esposo y más eterno acompañada" (1481), pero con la conciencia lúcida, atrozmente apesarada de que, en este mundo, ha tenido un esposo de quilates inigualables, una "perla" que ella, insensata, trágicamente, "threw away". 56 Al nuevo esposo va a pedirle consuelo $\mathrm{y}$, sobre todo, implorarle perdón por un error, por un ipecado!, que ella de seguro no podría perdonarse a si misma jamás. No queriendo ya saber nada del malévolo mundo en que le tocó vivir (Roque Guinart, quien en este momento representaría para ella los bandos de cualquier especie, "ofreciósele de acompañarla... No quiso su compañía Clara Jerónima, en ninguna manera...", 1481), de ese mundo que con sus feroces odios la convirtió a ella en asesina de su propio amor, Clara Jerónima "se despidió... llorando" (1481), para encerrarse en el monasterio, donde continuaría llorando "amaramente..., con interno dolore e sanguinose lacrime... li suoi infortuni, la morte del caro amante con la sua miseria insiemi, fin che il vivere gli fosse concesso". 57

En el conciso episodio cervantino se incorporan, sabiamente utilizados, los elementos fundamentales de la tragedia clásica (con algunos detalles y matices genuinamente sofocleos): conflictos y dilemas, ambigüedades y falacias, suspenso y sorpresas, anagnórisis, ironías y catarsis...58 Según algunos lectores, también está presente esa inexorable Fatalidad que a menudo destruye cruelmente a los mejores: Dice Roque Guinart: "Yo, de mi natural, soy

${ }^{54}$ F., Duc de la Rochefoucauld, Réflexions morales, p. 330. R. L. Hathaway dice que a este episodio del Quijote "le falta originalidad" "Claudia Jerónima", p. 319). Sin embargo, no menciona ningún antecedente. Y aunque conociese los que indicamos en este estudio, y otros posibles, esa opinión sería muy desacertada, según esperamos haber demostrado.

55 Reacción parecida de Giulietta en la Istoria di due nobili amanti, p. 41. La tragedia de los amantes de Luigi da Porto, Bandello, Shakespeare produce efectos análogos en todos los testigos. Es natural. Sin embargo, es muy notable que "las tristes quejas de Claudia... sacaron las lágrimas de los ojos de Roque, no acostumbrados a verterlas en ninguna ocasión" (1481), pues también con este detalle se pone de relieve su bondad natural, de gran importancia para el retrato que de él hace Cervantes, según lo ha visto ya K. L. Selig ("Some Observations on Roque Guinart", p. 276).

56 Shakespeare, Othello, V, segunda escena. Desde nuestra perspectiva resulta extraña esta observación de L. Combet: "1'homme agresseur qui triomphe de la femme. C'est ce qui se produit encore dans l'histoire de la belle Claudia Geronima" (Cervantès ou les incertitudes du désir, p. 84).

57 Masuccio Salernitano, Novela XVI, en Novelle, Roma, Formiggini, 1929, p. 215. En esta obra se noveliza por primera vez [1476] la trágica muerte de Romeo y Julieta, con los nombres de Mariotto y Giannozza. Istoria di due nobili amanti, p. 43: Giulietta: "che debbo io senza te in vita più fare, signor mio?".

58 Sorprende que en su interesante Theatrical Aspects of the Novel: A Study of D. Quixote, J. Syverson-Stork no considere este episodio, tan eminentemente dramático, teatral. Para R. L. Hathaway, sin embargo, todo este episodio es sólo "una pequeña tragedia de errores..., teatralidad de opera o melodrama" (Claudia Jerónima, pp. 319, 326). 
compasivo y bien intencionado; pero... el querer vengarme de un agravio que se me hizo, así da con todas mis buenas inclinaciones en tierra, que persevero en este estado, a despecho y pesar de lo que entiendo" (1482). Y comenta Unamuno: "Roque se sentía atado a su oficio como a un sino fatal. Era su estrella". ${ }^{99}$ Ahora bien, Roque Guinart "reconoce la insolencia de su oficio" 60 y a la vez comprende, con perfecta claridad, que la causa directa de éste son esos "deseos de venganza, que tienen fuerza de turbar los más sosegados corazones" (1482), así como "turbaron" el de él. Reconoce que sus "buenas inclinaciones" y su "claro entendimiento" se demuestran débiles, impotentes frente al violento, corrosivo impulso vengativo. Reconoce, en suma, que su "mala estrella" es su propia debilidad moral y su renuncia a la razón. Es así que, lejos de poder gratificarle jamás en cualquier sentido, sus "venganzas" - penosamente irónicas ya por el hecho de que no sabe explicarse ni su razón ("no sé qué deseos de venganza"1482), pues se han vuelto en mera obligación, rutina de bando-, "se eslabonan" inextricable, incesante, incontrolablemente con otras "venganzas", llevándolo a una eventual inexorable destrucción moral y física. Esta es, pues, la "fatalidad" que se cierne sobre Roque Guinart -y, por implicación, sobre todos los bandos-, cuyas formidables fuerzas destructoras son de incalculable alcance. Sin embargo, ¡no son invencibles! Dice Roque Guinart: “...pero Dios es servido de que, aunque me veo en la mitad del laberinto de mis confusiones, no pierdo la esperanza de salir dél a puerto seguro" (1482). Una bella "estrella", de comprobadas virtudes milagrosas, podría, únicamente, orientarle hacia la salida, la redención: ¡el perdón! "¡Perdónanos nuestras ofensas como nosotros perdonamos a nuestros ofensores!” El perdón, aunque sólo de iniciativa individual, empezaría a "eslabonarse" con otros perdones, deteniendo por fin la monstruosa rueda de las mutuamente perpetradoras venganzas. Roque Guinar, "de natural compasivo y bien intencionado, y de buen entendimiento", mantiene su "esperanza", ¿ya vislumbrando el bello resplandor de esa mágica "estrella"? Quizás lo vislumbre, pero al fin del episodio lo vemos todavía muy escéptico respecto a la posibilidad de una reconcilicación, de la paz entre los feroces bandos catalanes. En su carta a Antonio Moreno parece revelarse cierto humor cínico al encarecer "las locuras y discreciones de don Quijote", que, con "los donaires" de Sancho, "no podían dejar de dar gusto general a todo el mundo", sin excluir a sus enemigos, los Cadells (1484). La inclusión de éstos responde a una ulterior ocurrencia de Roque Guinart, debida, probablemente, a su certera intuición del enorme efecto "cómico" que tanto para los Nierros como para los Cadells tendrían esas "locuras y discreciones" de D. Quijote respecto a la posibilidad de acabar con la guerra de los bandos y de una reconciliación entre ellos: "...que dejasen ese modo de vivir tan peligroso así para el alma como para el cuerpo...; el principio de la salud está en conocer la enfermedad y querer tomar el enfermo las medicinas..."(1481-82). Tales "pláticas" de seguro "no les entrarían bien" ni a los Nierros ni a los Cadells, no por

Roque Guinart confiesa que vive en un "laberinto de confusiones"; los amores de Claudia Jerónima y don Vicente tienen desenlace trágico por las confusiones de aquélla. ¿Sería éste acaso el asunto de La confusa, obra dramática perdida de que Cervantes habla con tanto orgullo (El viaje del Parnaso, p. 81)? Tal posibilidad se sustenta mucho también por la aguda observación de F. Rodríguez Marín de que "el relato de Clara Jerónima está lleno de endecasilabos sueltos", que "suena" de continuo a "verso" (ver V. Gaos, El ingenioso hidalgo Don Quijote de la Mancha, pp. 849 y 851). Según su práctica frecuente, Cervantes utilizaría el mismo asunto en géneros distintos; en éste caso, los "endecasílabos" preservados revelarian su uso original.

59 Unamuno, La vida de Don Quijote y Sancho, p. 328.

60 Ibid. 
"rústicos" de entendimiento como los "escuderos" (1481), sino, sobre todo, por una ceguera de la mente y una dureza del corazón, en que el odio, el rencor y la venganza los tenían esclavizados, constituyéndose ya en condición inherente, orgánica, personal y socialmente. Los prudentes, morales, sabios consejos con que Don Quijote desea ayudar a sus compatriotas - como, notablemente, en varias otras ocasiones semejantes en la $I T^{a}$ Parte de Quijote - 61 serían ridiculizados por ambos bandos, los auténticos locos, todos incapaces, por su orgullo, de dar el primer paso hacia el perdón, como mera humorada, en suma, como inútil, risible quijotería: “¡Pobre Don Quijote, paseado por la ciudad con tu ecce homo a espaldas!"62

"Ed allora si divise la città in due fazioni, come già era tutta Italia, cioè in Ghibellini e Guelfi, che fu l'ultima rovina di molte famiglie nobilissime, di modo che dapoi le discordie e le sétte tra le parti, e tra li nobili ed il popolo e tra popolani grandi ed il popol minuto, fecero varie e grandissime mutazioni, e sempre con spargimento di sangue grandissimo e rovine di bellissimi palazzi ed esilio di molti..." 63 Escueta referencia novelística a una notoria tragedia nacional, repetida, sin diferencias notables, con harta frecuencia, en muchos países. Francisco Manuel de Melo observa que los bandos de los Nierros y Cadells "no [eran] menos celebrados y dañosos a su patria que los Güelfos y Gibelinos" y otros bandos europeos y españoles. ${ }^{64}$ Así, evidentemente, piensa también Cervantes al contemplar esa interminable guerra fratricida, cruel sangria, frecuentemente, de los mejores hijos de Cataluña, de España.. Es, sobre todo, para dramatizar este hecho trágico que crea los fascinantes retratos de Roque Guinart y Clara Jerónima, ambos, esencialmente, víctimas, tanto por su propio sufrimiento como por el que -instrumentos imprudentes, indiscretos, reticentes o inconscientes del violento torbellino político- infligen a los otros. En sus incisivas fisonomías, proyectadas sobre el fondo negro, ominoso, deshumanizado del caos y de la violencia, se individualiza, de modo novelísticamente magistral, la terrible agonía colectiva, nacional. De una técnica esencialmente parecida se serviría Goya en su famosa pintura Tres de mayo.

61 Aventura de los pueblos rebuznadores; del morisco Ricote; de "las bodas de Camacho", entre otros ejemplos.

62 Unamuno, La vida de Don Quijote y Sancho, p. 330. Sólo teniendo en cuenta este hecho se puede explicar que "D. Antonio is a model of civility, a refined aristocrat whose idea of amusement, nontheless, is to put Quixote on display to throngs in the street" (L. A. Murillo, A Critical Introduction to Don Quixote, p. 241). Es parte fundamental del pensamiento de Cervantes de que cada individuo es, en definitiva, responsable de sus acciones, de su vida, por su libre albedrio. Así, Roque Guinart es, en definitiva, responsable de su bandolerismo, pese a todas las circunstancias que lo inducen a tal vida. Esta conclusión sobre la inferencia cervantina nos parece lógica, por todo el contexto, sin necesidad de evocar las polémicas teológicas de los dominicanos y molinistas sobre el libre albedrio (A. Weber, "Don Quixote with Roque Guinart", pp. 132-133). Al exaltar la "fe" de Roque Guinart en la "Gracia Divina", como medio suficiente para la "Salvación", identificándola con la del autor, J. Casalduero propone una actitud que nos parece insostenible, a base de todas las obras de Cervantes (Sentido y forma del Quijote, Madrid, Ínsula, 1966, pp. 355-356). Las sugerencias de Unamuno sobre el "sino fatal" de Roque Guinart, que se discute en relación con el "malhechor colgado junto a Cristo, San Dimás, Pablo de Tarso, Pablo el hermitaño, Enrico de Tirso de Molina, Martín Fierro, etc.", nos resultan, en gran parte, contradictorias. (La vida de Don Quijote y Sancho, pp. 321-329).

63 Bandello, Novela I, I Parte, p. 10.

64 Citado por Unamuno, La vida de Don Quijote y Sancho, p. 329. 
Como sucede a menudo en las obras cervantinas de todos los géneros, en este episodio del Quijote se entrelazan elementos "rigurosamente históricos" (las guerras de los bandos catalanes, Roque Guinart, etc.) con otros patentemente inventados, ficticios (D. Quijote, el encuentro de éste con Roque Guinart y Claudia Jerónima, los amores trágicos de ésta, etc.), sintentizándose todo en una armoniosa situación literaria que, simultáneamente, se revela como una ingeniosa, gráfica, original e importante metáfora de una deplorable faceta de la realidad histórica, política, social y moral de la España de los Felipes. Por virtud de esta sutil, ponderada combinación de lo "histórico" con lo imaginativo, ambos elementos se fecundan recíprocamente, novelizándose y dramatizándose lo "histórico" y, a la vez, "historizándose" lo ficticio, novelesco. El mismo procedimiento artístico, utilizado con igual intención, se aprecia, dentro del género novelístico, siglos después, en los Episodios nacionales de Galdós ${ }^{65}$ y en La guerra y la paz de Tolstoy, para recordar sólo algunos de los ejemplos más notables. Uno de los efectos más transcendentales de tal procedimiento es que la literatura, además de su intrínseco valor artístico, adquiere también el prestigio de fidedigna, auténtica fuente histórica. Exalta a este propósito Pío Baroja: "la tendencia de los escritores a buscar el conocimiento de un país en la literatura, y no en la historia y la estadística". Entre la lite-ratura más valiosa también en este sentido Baroja recomienda la de Cervantes. ${ }^{66}$

\section{Povzetek}

\section{ZVESTOBA DO GROBA: CLARA JERÓNIMA, VICENTE TORELLAS IN ROQUE GUINART (DON KIHOT, II. del, poglavji 60 in 61)}

Kot se pogosto dogaja $v$ najrazličnejših Cervantesovih delih, se tudi $v$ teh dveh poglavjih drugega dela Don Kihota prepletajo zgodovinski dogodki (boji med katalonskimi razbojniškimi tolpami, Roque Guinart itn.) s povsem izmišljenimi (Don Kihot, njegovo srečanje z zgodovinskimi osebami, tragična ljubezen). Cervantesova pripoved, v kateri se dopolnjujejo zgodovinski in izmišljijski elementi, predstavlja povsem izvirno metaforo zgodovinskega, političnega, družbenega in moralnega prereza takratne Španije. Torej tako zasnovano literarno delo predstavlja tudi neizčrpen in avtentičen zgodovinski vir.

65 Ver R. Gullón, "La historia como materia novelable", en Galdós: el escritor y la crítica, Madrid, Taurus, 1973, pp. 403-426. A. Sanchez se refiere al episodio de Ricote, del Cautivo y de Roque Guinart como "episodios nacionales cervantinos" ("Arquitectura y dignidad moral de la Segunda Parte del Quijote", Anales cervantinos, 1979-1980, pp. 10-11).

66 Pío Baroja, "La literatura y la historia", en Obras completas de Pio Baroja, Madrid, Bibl. Nueva, 1948, p. 1100. 